\title{
Structure and strength of a continental transform from onshore-offshore seismic profiling of South Island, New Zealand
}

\author{
Tim Stern ${ }^{1}$, David Okaya ${ }^{2}$, and Martin Scherwath ${ }^{1 *}$ \\ ${ }^{1}$ Institute of Geophysics and School of Earth Sciences, Victoria University of Wellington, P.O. Box 600, Wellington, New Zealand \\ ${ }^{2}$ Department of Geological Sciences, University of Southern California, Los Angeles, CA 90089-0740, U.S.A.
}

(Received January 18, 2002; Accepted July 19, 2002)

\begin{abstract}
Seismic images of deformation beneath South Island, New Zealand, are provided by a form of seismic exploration uniquely suited to the study of "continental islands"-double-sided, onshore-offshore seismic methods in conjunction with onshore refraction and teleseismic P-wave delay data. Four sets of independent observations and analysis are use to infer rock properties within this plate boundary zone: seismic and electrical indications of highfluid pressures within the crust; P-wave delays from teleseismic anisotropy to show a high-speed zone in the mantle directly below the crustal root; Pn anisotropy of $11 \pm 3 \%$ distributed over a region $>100 \mathrm{~km}$-wide; and an effective elastic thickness (Te) that is vanishingly small beneath the Southern Alps and surface outcrop of the Alpine Fault, but increases to values of $\mathrm{Te}>20 \mathrm{~km}$ beyond the coastlines of the South Island. Together, these observations show that deformation in the crust and mantle becomes progressively wider with depth. A region of distributed deformation $>200 \mathrm{~km}$ wide is inferred for the upper mantle. We propose that the weakness and the wide zone of deformation are phenomena of plate boundaries where both strike-slip and convergence have persisted for several millions of years.
\end{abstract}

\section{Introduction}

The structure and strength of continental transforms has been the focus of recent controversy (Scholz, 2000; Zoback, 2000). For example, the San Andreas fault paradox (Lachenbruch and Sass, 1980) revolves around there being no heat flow anomaly associated with the fault despite laboratory measurements suggesting average fault stresses of about 50 $\mathrm{MPa}$ throughout the seismogenic layer. This finding, and others on stress directions (Townend and Zoback, 2001) point to the San Andreas being a weak fault. Yet, despite being weak, portions of the San Andreas have been subjected to earthquakes that approach magnitude 8 in historic times. This observation offers new challenges to our views of the link between earthquake scaling and the strength of faults (Miller, 2001).

The central portion of the Alpine fault in South Island, New Zealand, offers a potentially fresh view into the problem of fault strength, seismicity and continental deformation in general. Similarities between the San Andreas fault and the Alpine fault have been previously noted (Hatherton, 1968; Scholz, 1977), the main difference being that the Alpine fault has about $10 \mathrm{~mm} / \mathrm{y}$ of convergence in its central portion, whereas the San Andreas fault is essentially strikeslip throughout most of its length. Both mantle and crustal seismicity are low in the central section of the Alpine fault

* Now at School of Earth and Oceanic Sciences, University of Victoria, P.O. Box 3055, Victoria BC, Canada.

Copy right $(\mathrm{C}$ The Society of Geomagnetism and Earth, Planetary and Space Sciences (SGEPSS); The Seismological Society of Japan; The Volcanological Society of Japan; The Geodetic Society of Japan; The Japanese Society for Planetary Sciences. and show no spatial relationship to the trace of the Alpine fault (Leitner et al., 2001). Some view the low seismicity in terms of a seismic gap with a major to great earthquake being imminent (Beavan et al., 1999). An alternative view is that strain release could be more distributed, in both space and time (Stern et al., 2001; Walcott, 1979).

In this paper we examine recent crustal structure results for the central South Island in terms of implications for the strength of the crust and mantle at and adjacent to the Australia-Pacific plate boundary. Rather than making direct measurements of stress or strain, we use seismic exploration to examine the shape, form and seismic properties of structures in both the mantle and crust. We quantitatively assess strength and rock properties using a variety of methods. These methods include seismic anisotropy, flexural strength from loading and an assessment of fluid pressures, from seismic and electrical observations, within the Alpine fault zone. 1.1 Tectonic setting

Since $45 \mathrm{Ma}$ the South Island has undergone dextral shear with displacements of $850 \mathrm{~km}( \pm 100 \mathrm{~km})$ (Sutherland, 1999). Its manifestation in crustal rocks include $\sim 460 \mathrm{~km}$ of slip on the Alpine fault (Fig. 1), and more diffuse shearing northwest and southeast of the fault. This shearing is reflected by the bending of belts of rock (terranes) (Sutherland, 1999), and internal rotations shown by paleomagnetic declination anomalies (Mumme and Walcott, 1985).

Present-day relative motion of the Pacific relative to the Australian plate is about $39 \mathrm{~mm} / \mathrm{y}$ of which about 12 and $35 \mathrm{~mm} / \mathrm{y}$ are the estimated rates perpendicular and parallel, respectively, to the plate boundary. About $100 \mathrm{~km}$ of shortening has occurred in the central South Island since $\sim 10 \mathrm{Ma}$ 


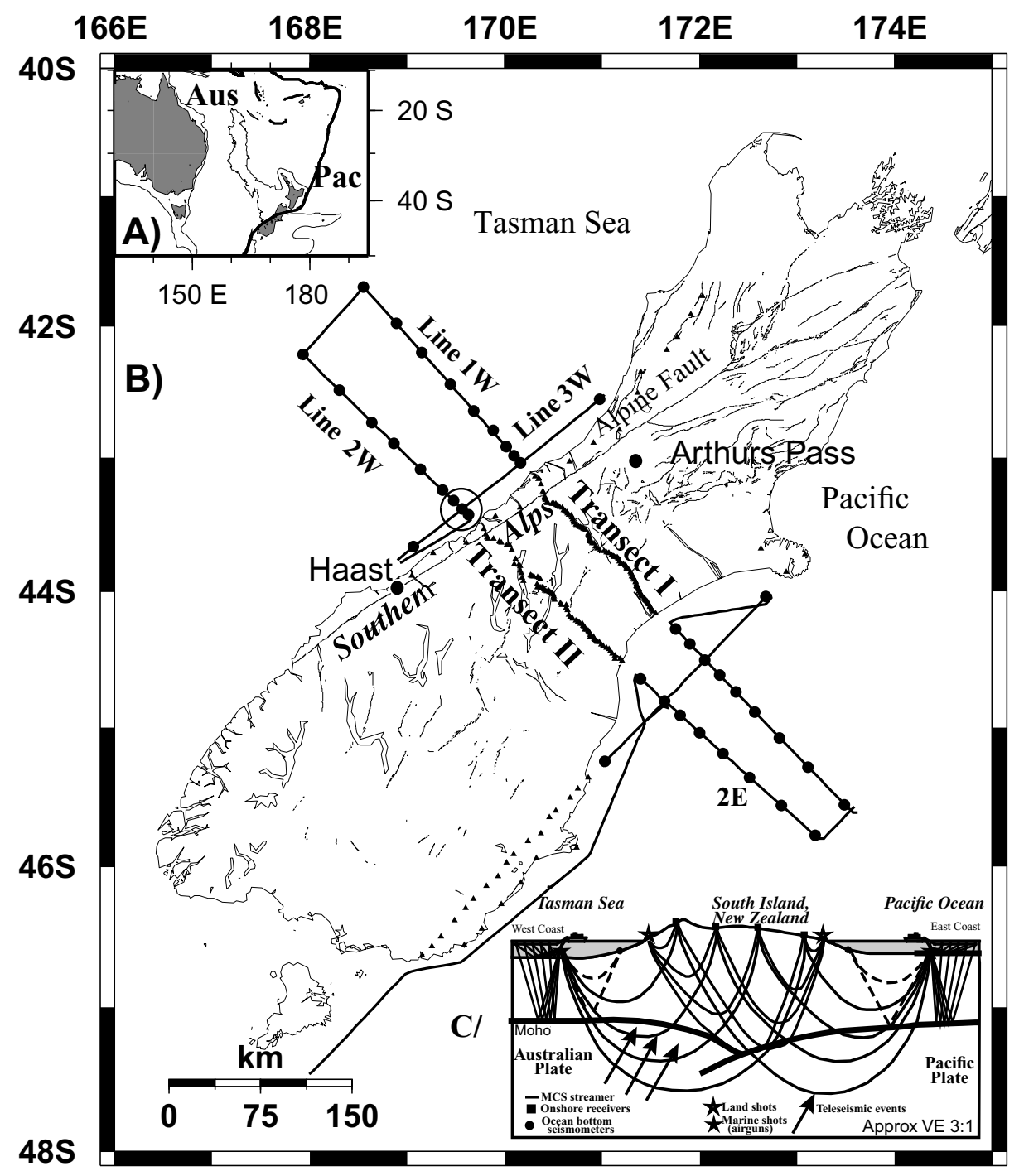

Fig. 1. (a) Plate boundary between Pacific (Pac) and Australian plates (Aus). (b) Map of South Island, New Zealand, showing ship lines, and transect 1 and 2 along which the SIGHT program was run. Solid circles in offshore regions represent OBS sites, Small circles on land represent seismograph localities that recorded the air gun shots. Approximately 160 seismographs were placed on line 1 and 2 for airgun shots and 400 seismographs were placed on each line for the refraction shots. Open large circle at intersection of lines $2 \mathrm{~W}$ and $3 \mathrm{~W}$ represents the region where Pn speeds were determined on mutually perpendicular lines and a $11.5 \%$ anisotropy for Pn calculated (see text). (c) Cross section view of the South Island showing the coverage of rays from coast to coast and the near vertical rays from teleseismic events from the western Pacific.

with most of this in the past 6 my. (Walcott, 1998). As a consequence of the collision, the Southern Alps have formed with maximum elevations $>3000 \mathrm{~m}$, although heavy erosion and incision has reduced their average elevation in the central section to only $\sim 1600$ m (Koons, 1993).

\section{Crustal Structure from the SIGHT Programme}

A joint US-NZ crustal structure programme, SIGHT (South Island GeopHysical Transect) took place in 199698 (Davey et al., 1997; Stern et al., 1997). What made the SIGHT programme unique was the two-sided onshoreoffshore component that allowed efficient coast to coast imaging. Active source seismic methods across "continental islands" provides unusually high resolution of crust and upper mantle structure (Okaya et al., 2002). Optimal resolution is gained when the width of the island is $\sim 100-250$ $\mathrm{km}$, because at this width powerful, ship-mounted air gun arrays, deployed each side of the island, provide complete coast to coast coverage of the crust and mantle beneath the island (Figs. 1 and 2).

Programs of passive seismology, magnetotelluric and electrical studies, petrophysics as well as crustal-scale reflection profiling, and refraction-wide-angle reflection profiling were associated with the SIGHT study. Dynamite sources of $\sim 1000 \mathrm{~kg}$ were used on land, the reflection/wide angle work was anchored by marine multichannel seismic (MCS) profiling, and both onshore seismographs and ocean-bottom seismometers (OBS) recorded the MCS airgun sources. These studies were collected in 1996 along two parallel transects across the central South Island (Fig. 1). Combining the onshore-offshore experiment on each side of the Island with the land refraction profiles permited "super gathers" (Fig. 2) of approximately $600 \mathrm{~km}$ in length to be created (Okaya et al., 2002).

Teleseismic events from the western Pacific were recorded across our seismograph arrays and these data provided im- 


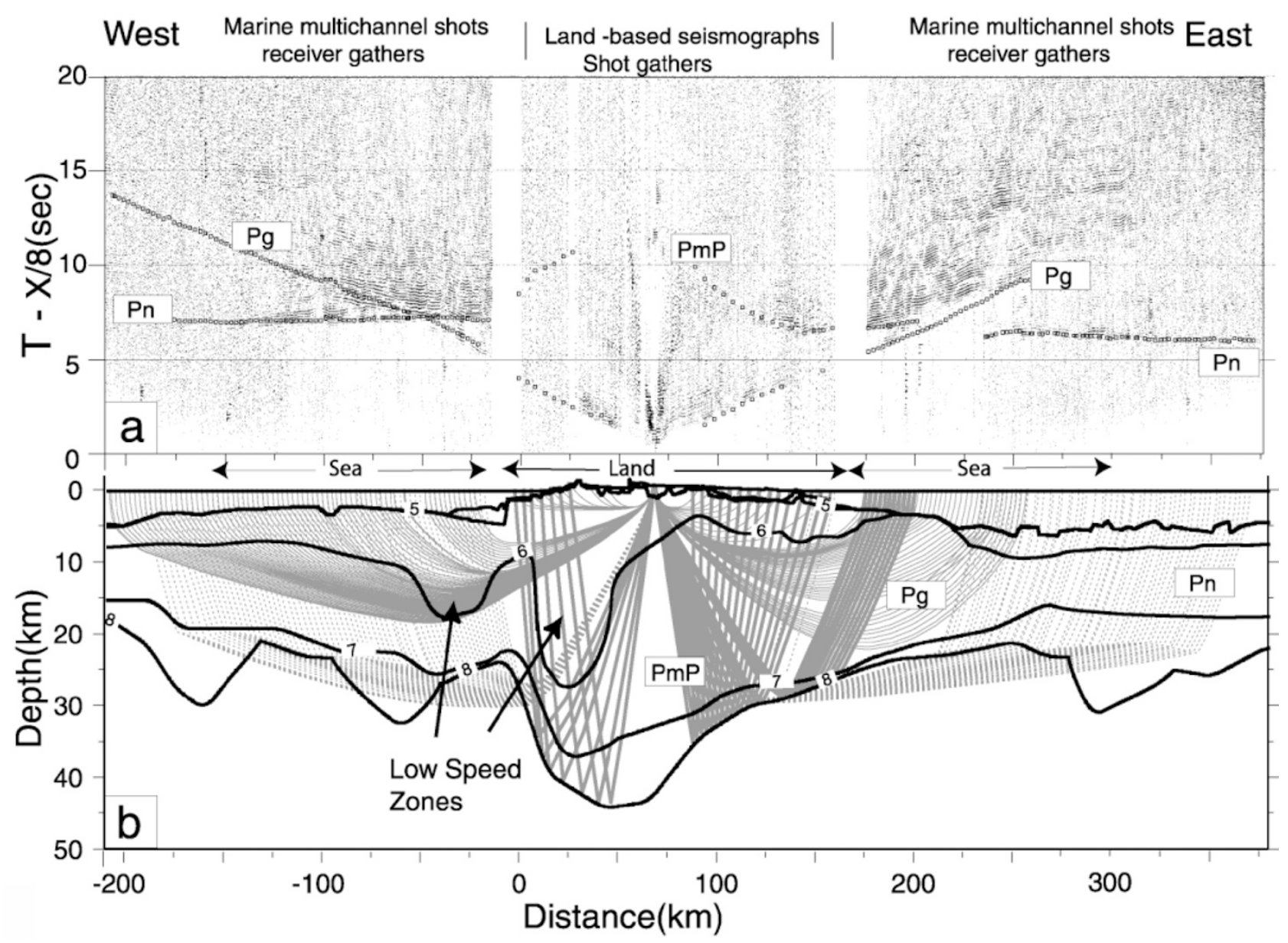

Fig. 2. A "supergather" centered on the middle of transect II (Fig. 1(b)). The middle section of data represents a shot-gather from land shot 25 , recorded by 400 seismographs. Data from the offshore regions represents receiver-gathers from a single seismograph located at shot point 25 , but recording $\sim 4000$ air gun shots from each side of the island. Data reduced at $8 \mathrm{~km} / \mathrm{s}$. Model at bottom is based on 7 shot gathers and about 50 receiver gathers. Note the low-speed zones in the crust.

portant constraints on structure of the mantle beneath the South Island. Because the teleseismic waves are coming up through the crust at a steep angle, they also illuminated structure within the Alpine Fault Zone in a useful way (Fig. 1(c)).

Most of the collected data from SIGHT possess high signal to noise ratio with strong Pn phases recorded to offsets of $\sim 300 \mathrm{~km}$. Powerful PmP reflections from both air guns and dynamite shots and excellent $\mathrm{SmS}$ and $\mathrm{PmS}$ phases were recorded from the airgun shots (Fig. 2).

Crustal structure Image:

A combination of forward modeling and tomographic inversion has produced crustal-upper mantle structure images of the plate boundary (fig. 2). Principal features to note are:

1. A crust that increases in thickness from $27 \mathrm{~km}$ at the coasts of the South Island to a maximum of $44 \mathrm{~km}$ just east of the main divide of the Southern Alps. Such an increase $(\sim 17 \mathrm{~km})$ in crustal thickness is nearly twice that required to isostatically support the average topography of the South Island.

2. Seismic wave speeds of $6-6.3 \mathrm{~km} / \mathrm{s}$ throughout most of the crust but two regions of lower wave speed directly beneath the alps and another low-speed region west of the west coast.
3. Seismic wave speeds of $\sim 8.1 \mathrm{~km} / \mathrm{s}$ in the mantle, except beneath and up to $100 \mathrm{~km}$ each side of the Alpine fault where strong anisotropy in $\mathrm{Pn}$ is detected (Scherwath et al., 2002). (see latter section).

These observations are directed to the study of the following processes:

\subsection{Fault zone properties}

On the inversion of Fig. 2 the low-speed zone beneath the Southern Alps is spread over a wide area and has drop in speed of just a few percent. However, when analyzed shot by shot the low-speed zone is more confined and more intense than the inversion of Fig. 2 suggests (Fig. 3). Delays in wideangle reflections, direct turning Pg arrivals through the crust (Smith et al., 1995; Stern et al., 2001) and from teleseismic P-wave arrivals (Stern et al., 2000) all contribute to defining a low-speed zone that is elongate and dips to the southeast. Maximum delay is $0.8 \mathrm{~s}$ over a path length of about $50 \mathrm{~km}$, which corresponds to a $10 \%$ reduction in $\mathrm{P}$-wave speed for $V p \sim 6 \mathrm{~km} / \mathrm{s}$. The low-speed region coincides with the down-dip extension of the surface trace of the Alpine Fault, as defined by strong reflectivity (Kleffmann et al., 1998).

Anisotropy is not required to explain the low-velocity zone as it is defined by mutually perpendicular rays (Fig. 3). 


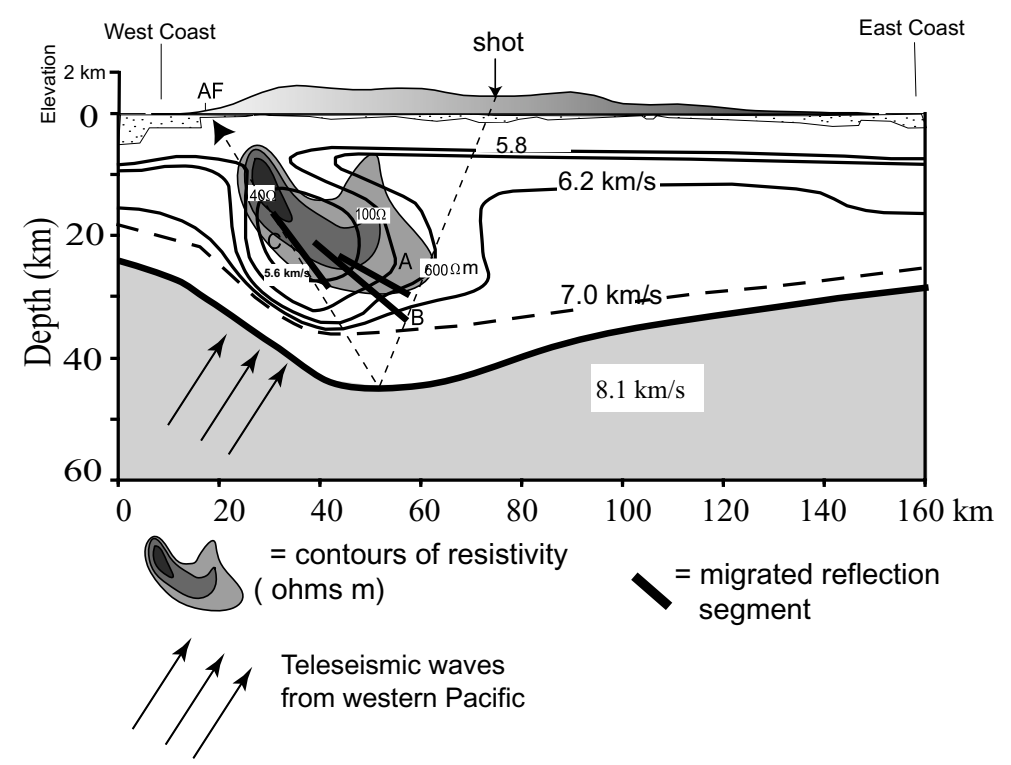

Fig. 3. Crustal structure model showing low-speed region in crust that satisfies wide-angle reflections and teleseismic delays (Stern et al., 2001; Stern et al., 2000). Contours of wave speed shown by solid and dashed lines $(\mathrm{km} / \mathrm{s})$. Shading represents apparent resistivity ranging from 40 ohm-m for darkest zone to $600 \mathrm{ohm}-\mathrm{m}$ for lightest. Zones of strong crustal reflectivity shown as migrated reflection bands (after Stern et al. (2001)). Lightly -dashed lines represent indicative ray-path for wide angle reflections and $\mathrm{P}$-wave delays.

Fault gouge and temperature effects are also rejected as possible causes of the low-speed zone (Stern et al., 2001). Instead, high fluid pressure is postulated as the source of the low-velocity zone; laboratory data show, for low porosity crustal rocks, enhanced pore pressure will lower the compressional velocity by $10 \%$ when the pore pressure approaches lithostatic (Jones and Nur, 1984). A fluid origin for the low-speed zone is further supported by a magnetotelluric study (Wannamaker et al., 1998) along line 1 that shows a region of low $(\sim 40 \mathrm{ohm}-\mathrm{m})$ resistivity in the crust that is approximately coincident with the low-speed zones (Fig. 3). Interconnected fluid is required to maintain the magnetotelluric anomaly, whereas fluid under a pressure approaching lithostatic is required to reduce seismic wave speeds by the requisite $10 \%$.

One of the consequences of enhanced fluid pressures in the crust is the effect on fault strength. The condition for sliding to occur on a pre-existing plane is (Hubbert and Rubey, 1959):

$$
\tau_{f}=F\left(T_{n}-P_{f}\right)
$$

where $\tau_{f}$ is the shear traction at failure, $F$ is the coefficent of friction, $T_{n}$ is the normal traction on the fault and $P_{f}$ is the fluid pressure. An increase in fluid pressure, therefore, can cause a corresponding decrease in the differential stress required for shear failure on a fault, or for an array of faults that make up a fault zone (Rice, 1992).

\subsection{Low speed zone, high fluid pressure and seismicity}

Crustal seismicity is restricted to the top $8 \mathrm{~km}$ directly beneath the Alpine Fault (Leitner et al., 2001), which is the depth at which the top of the low speed zone is detected. Thus a straightforward interpretation of the scarcity of seismicity below $8 \mathrm{~km}$ is that fluid pressure has reduced the shear stress within the fault zone such that any strain release is manifest either as low-frequency strain outside of the seismic radiation band width (i.e. slow earthquakes), or as earth- quakes below the $M s>3.0$ threshold for the survey of Leitner et al.

At the north and southern ends of the central section of the Alpine fault (Arthurs Pass and Haast (Fig. 1), respectively), topography and rock uplift (Kamp and Tippett, 1993) diminish. But at both Haast and Arthurs Pass large $(M s>6.5)$ earthquakes have been recorded in historical times and south and north, respectively, of these two localities the level of crustal seismicity increases (Anderson and Webb, 1994). Hence, we interpret the broad area of low seismic wavespeeds east of the central section of the Alpine Fault to be an indicator of excess fluid brought about by collision, thickening and prograde metamorphism of the greywacke-schist rocks of the crust. The central Southern Alps low-velocity zone could act as a cushion, effectively dissipating throughgoing ruptures by distributing strain more evenly in both space and time as has recently been demonstrated for other plate boundaries where fluid pressures are high (Burgmann et al., 2001; Heki et al., 1997; Kanamori and Kikuchi, 1993).

\section{Mantle Structure and Deformation}

During the onshore-offshore shooting of the SIGHT program 160 seismographs were left running in continuous mode for about 7 days. During this period, 3 earthquakes from the western Pacific of $M s \geq 5.0$ were recorded. As the azimuth of the western Pacific to the west coast of the South Island is almost identical to that of the seismic lines (Fig. 1), arrivals from these teleseismic events are treated like in-line shots, albeit with a large offset and a small incident $\left(\sim 25^{\circ}\right)$ angle. Data were processed in the regular way to produce plots of teleseismic P-wave delays along both lines across the central South Island (Stern et al., 2000). Only the broad details of this study are repeated here.

Two distinct trends (Fig. 4(a)) can be seen in the teleseismic delays: an increase due to thickening of the crust beneath 


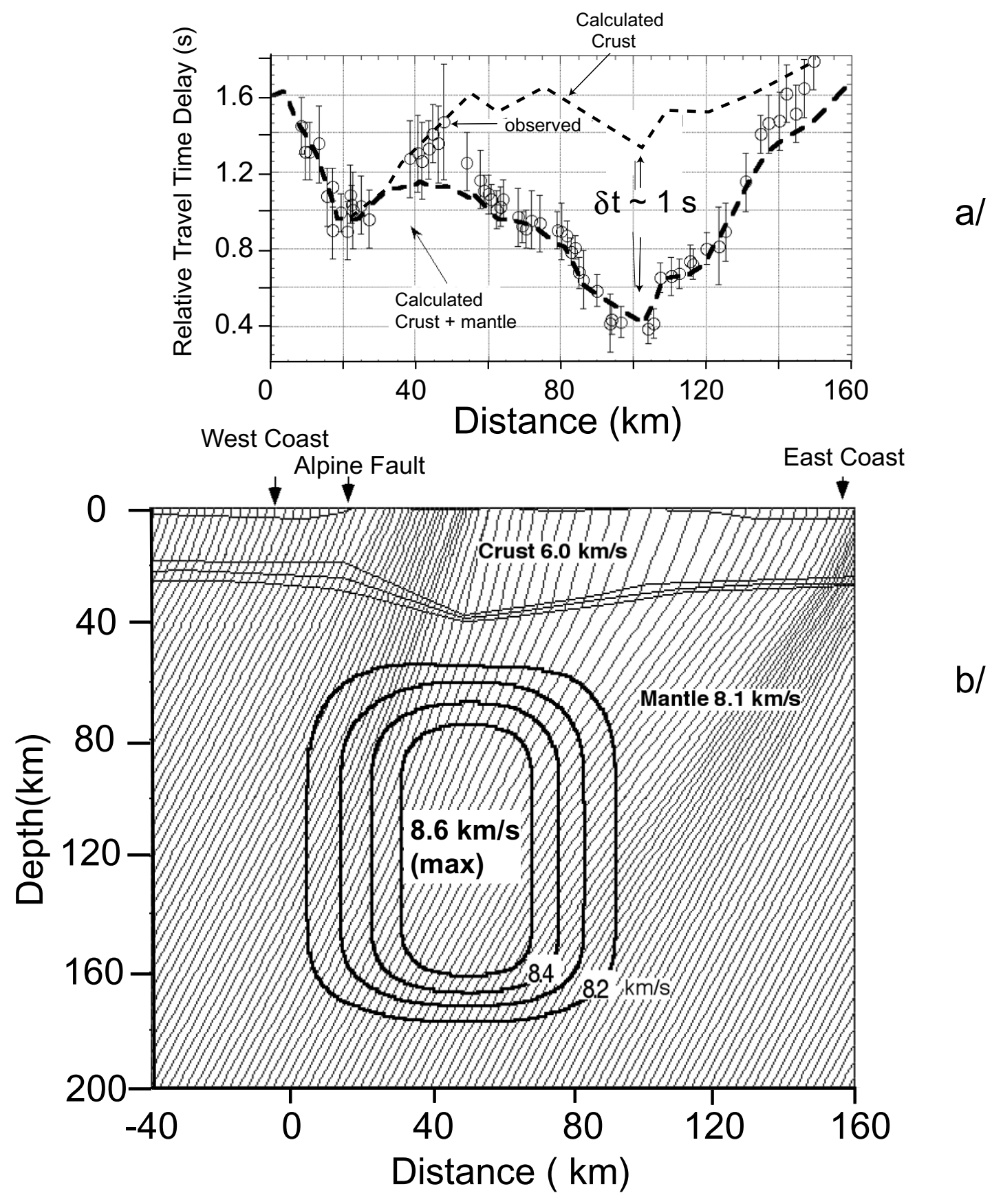

Fig. 4. (a) P-wave delays recorded across transect 1 from Honshu earthquake. Delays are with respect to a standard earth model given by the IASP91 model (Kennett and Engdahl, 1991). Note the positive delay (slowdown) associated with the crustal root then the major speed-up of $(\sigma t=1 \mathrm{~s})$ that peaks at $\mathrm{km} \mathrm{100.} \mathrm{Lightly} \mathrm{dashed} \mathrm{line} \mathrm{represents} \mathrm{fit} \mathrm{for} \mathrm{crustal} \mathrm{structure} \mathrm{only.} \mathrm{Heavy-dashed} \mathrm{line} \mathrm{represents} \mathrm{fit} \mathrm{of} \mathrm{both} \mathrm{crust} \mathrm{and} \mathrm{mantle} \mathrm{structure.} \mathrm{(b)} \mathrm{Crustal}$ structure model and mantle high-speed anomaly that satisfies observed P-wave delay data. The mantle anomaly can be modelled as a symmetrical body situated directly beneath the crustal root with a maximum speed increase of $\sim 7 \%(8.6 \mathrm{~km} / \mathrm{s})$ with respect to the regular mantle speed of $8.1 \mathrm{~km} / \mathrm{s}$.

the Southern Alps (km 20-50) and then the delays reduced by nearly a second from $\mathrm{km} 40$ to a minimum at $\mathrm{km} 100$. Such a large decrease in $\mathrm{P}$-wave delays requires a region of high seismic wave-speed in the mantle. Of particular note is that if one traces a ray back into the earth from the surface at $\mathrm{km} \mathrm{100,} \mathrm{the} \mathrm{ray} \mathrm{will} \mathrm{be} \mathrm{directly} \mathrm{beneath} \mathrm{the} \mathrm{root} \mathrm{of} \mathrm{the}$ alps when it is about $120 \mathrm{~km}$ deep (Fig. 4(b)). This is just the condition that would be predicted if the high speed region in the mantle is due to uniform thickening of a $100 \mathrm{~km}$ thick lithosphere that has been shortened by $\sim 100 \mathrm{~km}$ (Stern et al., 2000). i.e. the shortened and relatively cold, denser and faster mantle lithosphere is displaced into the hotter, less dense and slower asthenosphere.

Data from 3 earthquakes are reported for the two lines, giving 6 independent data sets. Analysis of all data sets suggest much the same structure - a symmetric body, 2$7 \%$ faster than the surrounding mantle, which is located directly beneath the crustal root (Fig. 4(b)). Our interpretation (Fig. 5(a)) of the shape and position of this high-speed zone in the mantle is that it represents mantle lithosphere that has thickened and deformed in a ductile and continuous fashion. This is in contrast to intracontinental subduction (Fig. 5(b)) 


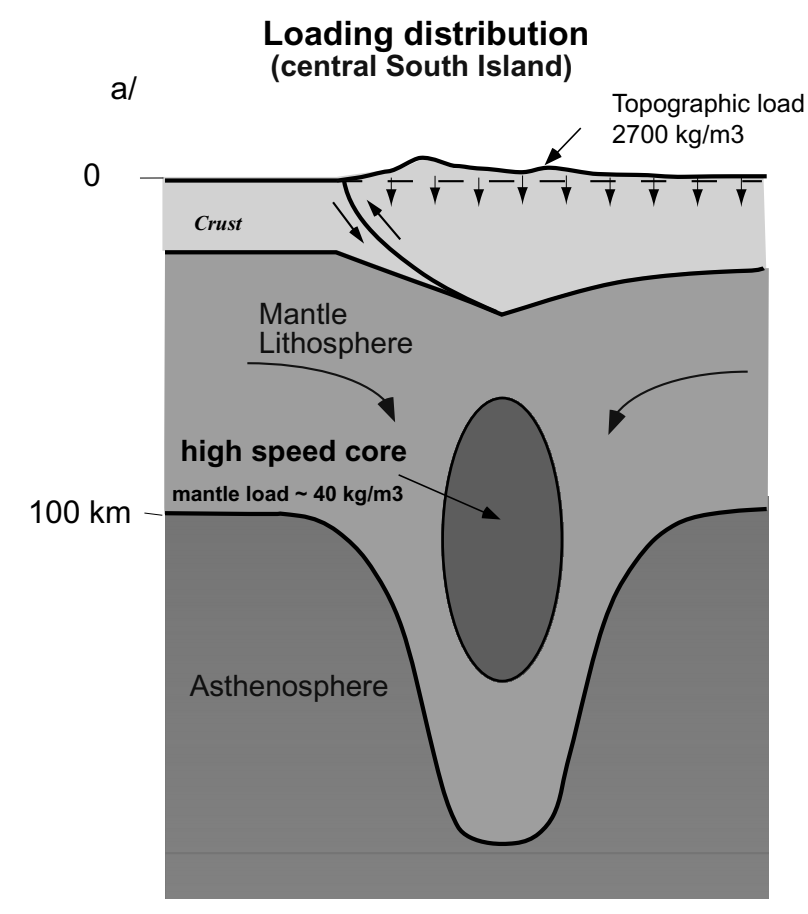

\section{b/ Intracontinental Subduction}

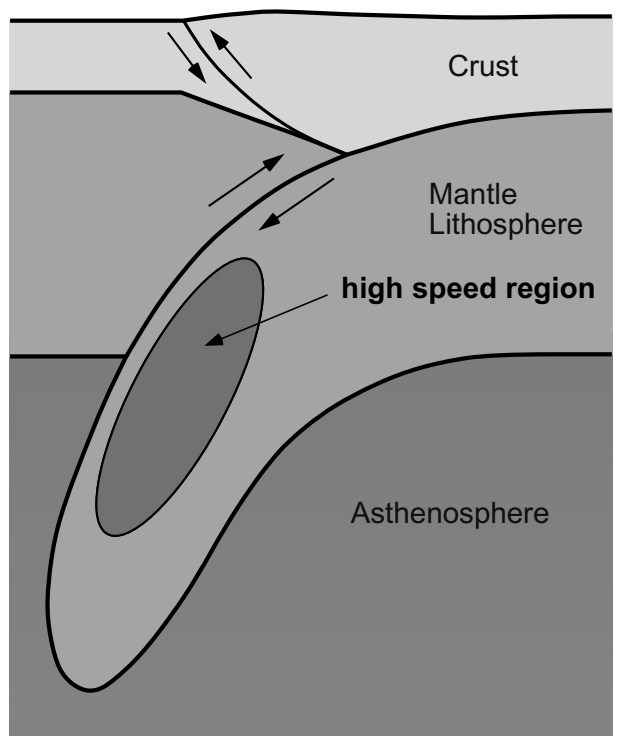

Fig. 5. (a) Cartoon showing how high-speed zone in asthenosphere represents thickened, cold, and therefore fast and more dense, mantle lithosphere. Loading on the Moho is therefore in the form of surface topography and subsurface loading from the cold and therefore more dense mantle blob. (b) Cartoon showing the process of intracontinental subduction as an alternative to distributed lithospheric thickening (Fig. 5(a)) as favoured by some (Beaumont et al., 1996).

that requires differential shear to be concentrated on a subduction thrust (e.g. Beaumont et al., 1996; Koons, 1990).

Such a ductile and weak rheology can be linked to the $45 \mathrm{Ma}$ of strike-slip shear that could cause both a pervasive heating (Stern et al., 2000) and/or dynamic recrystallisation in the mantle (Scherwath et al., 2002). The existence of a mantle "blob" (Figs. 4(b), 5(a)) is also evident from gravity anomaly data and requires an average density contrast of about $30 \mathrm{~kg} / \mathrm{m}^{3}$; a reasonable value for the contrast between mantle lithosphere and the asthenosphere (Stern et al., 2000).

\section{Pn Anisotropy}

Measurements of seismic anisotropy in the mantle make important contributions to understanding the strain history of an area, particularly if the depth range and amplitude of the anisotropy are well constrained (Silver, 1996). In the central South Island there are two new data sets that have a bearing on this problem: SKS splitting and Pn anisotropy. SKS splitting (Klosko et al., 1999) show some of the largest amplitudes and most consistent fast directions on the globe (Savage, 1999). However, the applicability of SKS data is limited as splitting can be due to anisotropy in either the asthenosphere or the overlying mantle lithosphere, if not both. An independent measurement of anisotropy that samples the mantle differently from shear waves propagating vertically through it is needed. Observations of $\mathrm{P}$-waves refracted in the upper mantle (Pn), adjacent to an active continental transform fault, allow such a measurement.

High quality Pn observations were made on mutually perpendicular lines $2 \mathrm{~W}$ and $3 \mathrm{~W}$ (Fig. 1) with the onshoreoffshore method. Speeds of 7.7 and $8.6 \mathrm{~km} / \mathrm{s}$ are calculated, respectively, by least squares with standard errors of
$0.14 \mathrm{~km} / \mathrm{s}$ (Scherwath et al., 2002). This amounts to an anisotropy of $11.5 \pm 2 \%$ and, according to the laboratory observations is high enough to suggest some degree of dynamic recrystallization to be taking place (Ismail and Mainprice, 1998; Ribe, 1992). Implications of this result are two-fold. Firstly, dynamic recrystallization can occur at the relatively low temperatures $\left(\sim 500^{\circ} \mathrm{C}\right)$ of the upper mantle with geological strain rates. Secondly, dynamic recystallization of the mantle will result in a reduction of grain size, and hence weakening by grain-size-sensitive flow (Rutter and Brodie, 1992). Grain size reduction would, however, encourage diffusion creep, and poorly developed seismic anisotropy (Savage, 1999). Thus our understanding of cause and effect between seismic anistropy and finite strain is still at an early stage.

Nevertheless, both Pn anisotopy and the ductile flow of the shortened mantle into a "blob" beneath the Southern Alps (Fig. 4) are seen as a consequence of a weakening of the mantle lithosphere. Two possible contributors to this weakening are: dissipative heating by distributed shear (see above) and/or grain size reduction by dynamic recrystallization.

\section{A Flexure Model for the Central South Island}

A broad measure of the gross strength of the central South Island lithosphere can be obtained by measuring the amplitude and wavelength of deformation induced by a known load. Our seismic studies have identified that the principal loading acting on the South Island is the "push" of topography and the "pull" of shortened mantle lithosphere (Fig. 5). A simple 2D gravity analysis shows that these two loads, although distributed in different ways, are similar in magnitude 


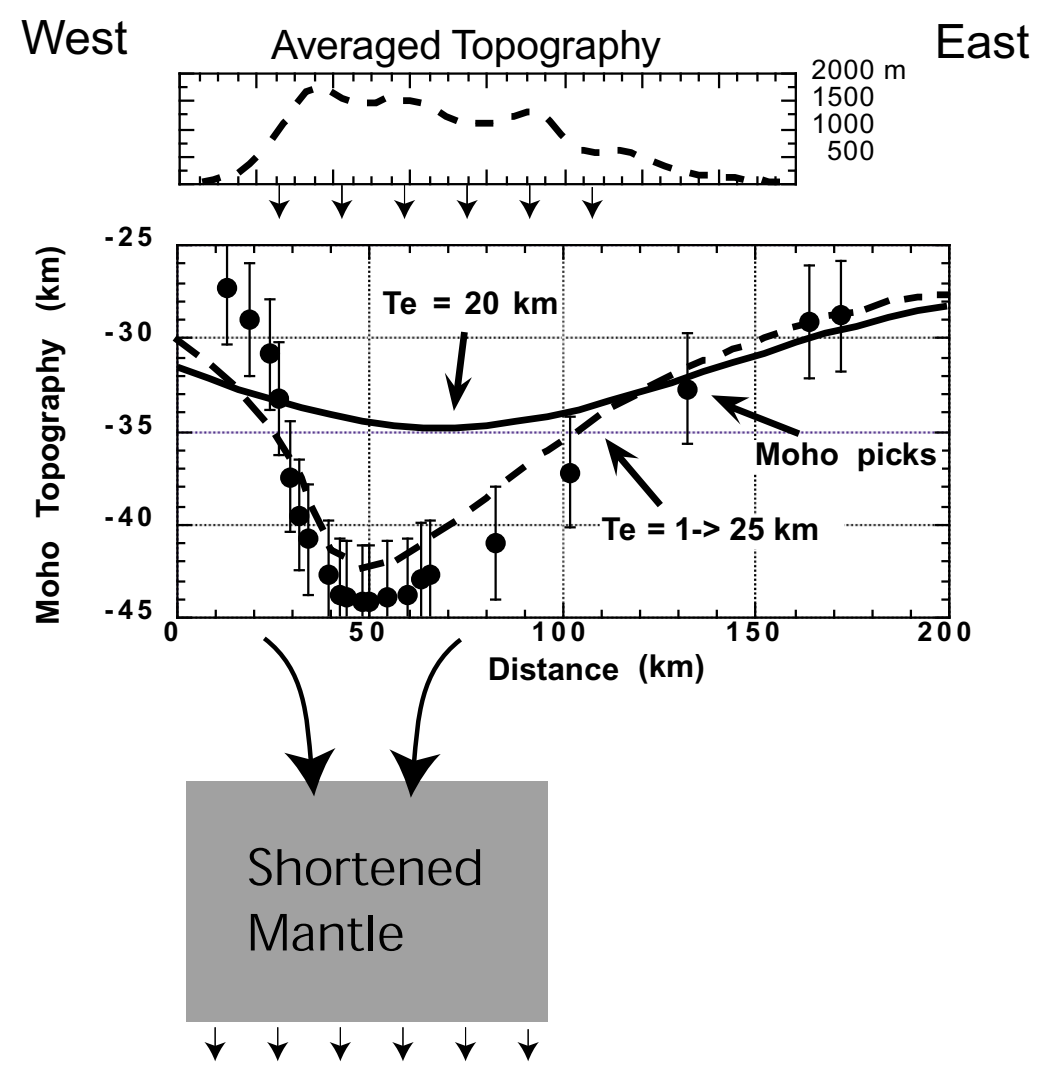

\section{Loading $=$ topography + shortened mantle}

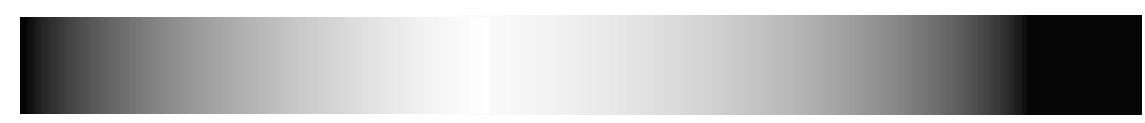

$$
\begin{gathered}
25 \ldots . .20 \ldots 10 \ldots \ldots \ldots . .1 \ldots 1 \ldots \ldots \ldots \ldots \ldots \ldots \ldots \ldots \ldots \ldots \ldots \\
\text { Te }(\mathrm{km}) \quad \text { Variation across central South Island }
\end{gathered}
$$

Fig. 6. Flexure model for deformation of the Moho, central South Island based on the shape of the Moho from seismic measurements. Loading is from both topography and the shortened mantle lithosphere. A continuous plate model is used and loading, elastic thickness (Te) and restoring force are allowed to vary in an arbitary fashion. Displacements (solid and dashed curves) are calculated using the finite difference code of Bodine et al. (1981) and compared to Moho pics (solid circles with $\pm 3 \mathrm{~km}$ errors bars). The Moho is assumed to have been flat and at a depth of $27 \mathrm{~km}$ prior to collision and loading. When both topographic and mantle loads are applied a Te variation shown by shaded bar at bottom is required to match (dashed curve) the observed Moho displacement. A constant $\mathrm{Te}=20 \mathrm{~km}$ (solid curve) fails to match both wavelength or amplitude.

\section{(Stern et al., 2000).}

We use the Moho as a reference surface for this study of loading. Implicit in doing this is the assumption that the Moho was flat prior to collision and loading. Our justification of assuming a flat, pre-Pliocene Moho is based on the geological record of central South Island. Late Miocene shallow-marine sediments are mapped in all but the central alps region, and shallow water terrestrial sediments (Glenntanner beds) of early Pliocene age (Gair, 1967) are exposed over a wide region of central South Island, including the Mt Cook region. Thus, prior to the main episode of loading at $\sim 6$ Ma muted topography and, therefore, a low relief Moho, are implied.

We start with a continuous elastic sheet where the effective elastic thickness (Te), loading and the restoring force from mantle buoyancy can be varied in an arbitary manner via finite difference techniques (Bodine et al., 1981). As we know the loading distribution, and the restoring force can be deduced from the surface geology, Te remains the sole variable to resolve from trial and error modeling.

The choice of a continuous plate, rather than a broken one is based on there being a wide zone of deformation in the mantle and lower crust, rather than a fault (Molnar et al., 1999). A continuous plate also permits a more general solution, as the ability of the finite difference technique to reduce Te to near zero values effectively permits us to approach the broken plate situation.

When both the topography and mantle blob are used as 
loads, and a constant effective elastic thickness (Te) of 20 $\mathrm{km}$, the resulting deflection clearly does not match the Moho topography (Fig. 6(b)). Only when we allow Te to drop to vanishingly small values in the central South Island do we get a reasonable match in both wavelength and amplitude (Fig. 6(b)). A value of $\mathrm{Te}=20 \mathrm{~km}$ is consistent with a well constrained loading study on the western platform of New Zealand (Holt and Stern, 1991). But values of Te $<5 \mathrm{~km}$ that are required in the central South Island suggest that there is effectively no elastic strength here, and all strain and deformation is taken up by either ductile flow or upper crustal faulting.

Also shown (Fig. 6(c)) is the predicted deflection of the Moho due to topography only, with the preferred Te variation shown in Fig. 6(d). Topography only provides loading to produce half the crustal root.

\section{Conclusions}

1. Double-sided onshore-offshore seismic imaging of continental structures is a powerful method of imaging continental islands such as South Island, New Zealand. The redundancy of ray paths provides coherency of crustal and mantle phases out to maximum offsets of $300 \mathrm{~km}$, depending on the air-gun and dynamite sources used. The method is highly suited to a number of other active plate boundary areas like Japan, central America and Summatra (Okaya et al., 2002).

2. First order discoveries of the SIGHT programme include the $\sim 17 \mathrm{~km}$ thick crustal root beneath the Southern Alps, and the $\sim 100 \mathrm{~km}$ thick lithospheric root, directly below the crustal root.

3. Second-order discoveries that have a bearing on rock rheology, fault strength and strain release include the discovery of a large low wave-speed zone in the crust beneath the Southern Alps and anisotropy of $11.5 \pm 2 \%$, in Pn values.

4. A flexural loading study allows us to quantify the inherent weakness in the crust and mantle. No elastic strength is indicated for the central South Island with a recovery to more normal values of $\mathrm{Te}$ at the east and west coasts.

5. A zone $200-400 \mathrm{~km}$ wide of distributed strain is suggested by the data presented here.

6. The profound weakness in the mantle of South Island is linked to the long history of strike-slip shear; either, or both, dynamic recrystallisation and dissipative shear heating may be responsible.

7. Weakening of the crust is more likely linked to the recent convergence, crustal thickening, prograde metamorphism and excess fluid release in the crust.

\section{References}

Anderson, H. and T. H. Webb, New Zealand seismicity patterns revealed by the upgraded National Seismic Network, N.Z. J. Geol. and Geophys., 37 477-493, 1994.

Beaumont, C., P. J. J. Kamp, J. Hamilton, and P. Fullsack, The continental collision zone, South Island, New Zealand; comparison of geodynamical models and observations, J. Geophys. Res., 100, 3333-3359, 1996.

Beavan, J., M. Moore, C. Pearson, M. Henderson, B. Parsons, S. Bourne, P. England, D. Walcott, G. Blick, D. Darby, and K. Hodgkinson, Crustal deformation during 1994-1998 due to oblique continental collision in the central Southern Alps, New Zealand, and implications for seismic potential of the Alpine Fault, J. Geophys. Res., 104, 25,233-25,255, 1999.

Bodine, J. H., M. S. Steckler, and A. B. Watts, Observations of flexure and rheology of the oceanic lithosphere, J. Geophys. Res., 86, 3695-3707, 1981.

Burgmann, R., M. G. Kogan, V. E. Levin, C. H. Scholz, R. W. King, and G. M. Steblov, Rapid seismic moment release following the 5 December, 1997 Kronotsky, Kamchatka, earthquake, Geophys. Res. Lett., 28, 13311334, 2001

Davey, F. J., T. Henyey, S. Holbrook, D. Okaya, T. Stern, A. Melhuish, S Henrys, H. Anderson, D. Eberhart-Phillips, T. McEvilly, R. Urhammer, F. Wu, G. Jiracek, P. Wannamaker, G. Caldwell, and N. Christensen, Preliminary results from a geophysical study across a modern, continentcontinent collisional plate boundary - the Southern Alps, New Zealand, Tectonophys., 228, 221-236, 1997.

Gair, H. S., Sheet 20 - Mt Cook. Geological map of New Zealand, 1:250,000, Department of Scientific and Industrial Research, Wellington, 1967.

Hatherton, T., Through the looking glass: a comparative study of New Zealand and California, Nature, 220, 660-663, 1968.

Heki, K., S. Miyazaki, and T. Hiromichi, Silent fault slip following an interplate thrust earthquake at the Japan trench, Nature, 386, 595-597, 1997.

Holt, W. E. and T. A. Stern, Sediment loading on the Western Platform of the New Zealand continent: Implications for the strength of a continental margin, Earth Planet. Sci. Lett., 107, 523-538, 1991.

Hubbert, M. K. and W. W. Rubey, Role of Fluid pressure in mechanics of overthrust faulting, Bull. Geol. Soc. Am., 70, 115-166, 1959.

Ismail, W. B. and D. Mainprice, An olivine fabric database: an overview of upper mantle fabrics and seismic anisotropy, Tectonophys., 296, 145157, 1998.

Jones, T. D. and A. Nur, The nature of seismic reflections from deep crustal fault zones, J. Geophys. Res., 89, 3153-3171, 1984

Kamp, P. J. J. and J. M. Tippett, Dynamics of Pacific Plate crust in the South Island (New Zealand) zone of oblique continent-continent convergence, J. Geophys. Res., 98, 16,105-16,118, 1993.

Kanamori, H. and M. Kikuchi, The 1992 Nicaragua earthquake: a slow tsumami earthquake associated with subducted sediments, Nature, $\mathbf{3 6 1}$ 714-716, 1993.

Kennett, B. L. N. and E. R. Engdahl, Travel times for global earthquake location and phase identification, Geophys. J. Int., 105, 429-465, 1991.

Kleffmann, S., F. Davey, A. Melhuish, D. Okaya, and T. Stern, Crustal structure in the central South Island from the Lake Pukaki seismic experiment, N. Z. J. Geol. and Geophys., 41, 39-49, 1998.

Klosko, E. R., F. T. Wu, H. J. Anderson, D. Eberhardt-Phillips, T. V. McEvilly, E. Audoine, and M. K. Savage, Upper mantle anisotropy in the New Zealand region, Geophys. Res. Lett., 26, 1497-1500, 1999.

Koons, P. O., Two-sided orogen; collision and erosion from the sandbox to the Southern Alps, New Zealand, Geology, 18, 679-682, 1990.

Koons, P. O., Three-dimensional critical wedges: Tectonics and topography in oblique collisional orogens, J. Geophys. Res., 99, 12,301-12,315, 1993.

Lachenbruch, A. H. and J. H. Sass, Heat flow and energetics of the San Andreas fault zone, J. Geophys. Res., 85, 6185-6222, 1980.

Leitner, B., D. Eberhart-Phillips, H. Anderson, and J. Nableck, A focussed look at the Alpine fault, New Zealand: seismicity, focal mechanisms, and stress observations, J. Geophys. Res., 106, 2193-2220, 2001.

Miller, S. A., Earthquake scaling and the strength of seismogenic faults; can pore pressures be inferred from earthquake rupture properties?, Proceeding of Int. Symp. on Slip and Flow processes in and below the Seismogenic Zone, Sendai City, Japan, November 2001, Published by Ministry of Education, Culture, Sports, Science and Technology, Japan, 2001.

Molnar, P., H. Anderson, E. Audoine, D. Eberhart-Philips, K. Gledhill, E. Klosko, T. McEvilly, D. Okaya, M. Savage, T. Stern, and F. Wu, Continuous deformation versus faulting through the continental lithosphere of New Zealand, Science, 286, 516-619, 1999.

Mumme, T. C. and R. I. Walcott, Paleomagnetic studies at Geophysics Division, 1980-813, Department of Scientific and Industrial Research, 1985.

Okaya, D., S. Henrys, and T. Stern, Double-sided onshore-offshore seismic 
imaging of Plate Boundary: Super-gathers across South Island of New Zealand, Tectonophys., 355, 247-263, 2002.

Ribe, N. M., On the relation between seismic anisotropy and finite strain, $J$. Geophys. Res., 97, 8737-8747, 1992.

Rice, J. R., Fault stress states, pore pressure distributions, and the weakness of the San Andreas fault, in Fault Mechanics and the Transport Properties of Rocks, edited by B. Evans and T. F. Wong, pp. 475-504, Academic Press, New York, 1992.

Rutter, E. H. and K. Brodie, Rheology of the lower crust, in The Lower Continental Crust, Developments in Geotectonics 23, edited by D. M. Fountain, R. Arculus, and R. Kay, pp. 201-268, Elsevier, Amsterdam, 1992.

Savage, M. K., Seismic anisotropy and mantle deformation: what have we learned from shear wave splitting studies, Rev. Geophys., 27, 64-106, 1999.

Scherwath, M., A. Melhuish, T. Stern, and P. Molnar, Pn anisotropy and distributed upper mantle deformation associated with a continental transform fault, Geophys. Res. Lett., 29, 16-1-16-4, 2002.

Scholz, C., Transform fault systems of California and New Zealand: similarities in their tectonic and seismic styles, J. Geol. Soc. Lond., 133, 215-229, 1977.

Scholz, C., Evidence for a strong San Andreas fault, Geology, 28, 163-166, 2000.

Silver, P. G., Seismic anisotropy beneath the continents: probing the depths of geology, Ann. Rev. Earth Planet. Sci., 24, 385-432, 1996.

Smith, E. G. C., T. Stern, and B. O’Brien, A seismic velocity profile across the central South Island, New Zealand, from explosion data., N.Z. J. Geol. and Geophys., 38, 565-570., 1995.

Stern, T. A., P. E. Wannamaker, D. Eberhart-Phillips, D. Okaya, and F. J. Davey, Mountain building and active deformation studied in New
Zealand, EOS, Transactions, American Geophysical Union, 78, 329,335336, 1997.

Stern, T. A., P. Molnar, D. Okaya, and D. Eberhart-Phillips, Teleseismic P-wave delays and modes of shortening the mantle beneath the South Island, New Zealand, J. Geophys. Res., 105, 21,615-21,632, 2000.

Stern, T., S. Kleffmann, D. Okaya, M. Scherwath, and S. Bannister, Low seismic wave-speeds and enhanced fluid pressure beneath the Southern Alps, New Zealand, Geology, 29, 679-682, 2001.

Sutherland, R., Cenozoic bending of New Zealand basement terranes and Alpine Fault displacement: a brief review, N.Z. J. Geol. and Geophys., 42, 295-302, 1999.

Townend, J. and Z. Zoback, Implications of earthquake focal mechanisms for the frictional strength of the San Andreas fault system, in The Nature and Tectonic Significance of Fault Zone Weakening, edited by R. E. Holdsworth, R. A. Strachan, J. F. Magloughlin, and R. J. Knipe, Special Publication of the Geological Society of London, 186, pp. 13-22, 2001.

Walcott, R. I., Plate motion and shear strain rates in the vicinity of the Southern Alps, in The Origin of the Southern Alps, vol. 18, edited by R. I. Walcott and M. M. Cresswell, pp. 5-12, R. Soc. N.Z. Bull., Wellington, 1979.

Walcott, R. I., Modes of oblique compression: late Cenozoic tectonics of the South Island of New Zealand, Reviews of Geophysics, 36, 1-26, 1998.

Wannamaker, P. E., G. R. Jiracek, J. A. Stodt, T. G. Caldwell, V. M. Gonzalez, J. D. McKnight, and A. D. Porter, Fluid generation and pathways beneath an active compressional orogen, the New Zealand Southern Alps, inferred from magnetotelluric data, EOS Trans. AGU, 79, F903, 1998.

Zoback, M., Strength of the San Andreas, Nature, 405, 31, 2000.

T. Stern (e-mail: tim.stern@vuw.ac.nz), D. Okaya, and M. Scherwath 